Fecha de recepción: octubre 2019 Fecha de aceptación: diciembre 2019 Versión final: diciembre 2021
La práctica de vestir a la Mamita: legitimidades, identidades y arte popular en el caso de la Virgen de Urkupiña en la ciudad de Salta-Argentina

Daniela Nava Le Favi ${ }^{1}$

\begin{abstract}
Resumen: El trabajo intenta pensar la construcción de identidades y legitimidades a partir de la práctica de vestimenta del culto a la Virgen de Urkupiña en la ciudad de Salta. La indagación retoma los abordajes en comunicación y cultura de América Latina, estudios culturales, semióticos y sobre religiosidad desde vertientes antropológicas, históricas y sociológicas. El objetivo del artículo es mirar los gustos legítimos de las agencias en la práctica de vestir la imagen: en el caso de Urkupiña posee una configuración rizomática y comunitaria que también está inscripta en una industria del creer especifica de la devoción. Este proceso habilita a comprender cómo determinadas formas estéticas hablan de algunos intersticios de lo que se considera "arte popular" el cual se teje en y desde disputas, contestaciones y consentimientos a las lógicas de dominación en estrecha relación a las formas en las que se expresan y re-afirman las identidades sociales y religiosas.
\end{abstract}

Palabras clave: Identidades - Legitimidades - Arte popular - Industrias del creer - Cultos marianos.

[Resúmenes en inglés y portugués en la página 195]

(1) Daniela Nava Le Favi: Doctora en Comunicación por Universidad Nacional de La Plata. Licenciada en Ciencias de la Comunicación por la Universidad Nacional de Salta (UNSa). Becaria Posdoctoral del CONICET. Lugar de trabajo: Instituto de Bio y Geociencias del NOA. Auxiliar docente en las cátedras de Semiótica General, Semiótica de la Cultura y Análisis del Discurso en la carrera de Ciencias de la Comunicación de la UNSa. Mail: danielanavalefavi@gmail.com

\title{
El caso
}

Es 15 de agosto y las procesiones en honor a la Virgen de Urkupiña colman la ciudad de Salta en Argentina. Este culto, cuyo origen mítico surge en la etapa colonial boliviana, ha migrado a diferentes lugares, entre ellos la zona del noroeste argentino. El paso de una 
frontera a otra ha producido numerosos procesos e traducción del ritual por lo cual, hablar de la "Mamita", requiere ciertas especificaciones sobre su configuración en el ámbito local. En Salta la práctica adquiere múltiples matices: mientras que en Cochabamba-Quillaicollo, es una festividad tradicional que implica la participación de miembros eclesiales y políticos; en la ciudad argentina es más bien una devoción rizomática que permanentemente se territorializa en la ciudad ${ }^{1}$ y que posee una dinámica que oscila entre lo popular - comunitario ${ }^{2}$ y lo masivo legible en los múltiples productos pertenecientes a una industria del creer (Algranti, 2013) más bien paralela ${ }^{3}$ (Guardia Crespo, 2003), es decir, elementos sagrados que no son compartidos con otras de las creencias católicas canónicas locales (Nava Le Favi, 2018). De este modo, el culto moviliza productos tales como alasitas, sahumerios, inciensos, y todos los elementos del ropaje de la Virgen: vestidos de diversos tamaños, colores y modelos; cetros, coronas, anillos de materiales diversos (alpaca, oro, plata), andas, entre otras. Estos productos, además, pueden ser construidos por los mismos devotos o suelen encargarlos a los negocios que comercializan este tipo de indumentaria, las cuales se hacen de acuerdo a los gustos de los promesantes.

Frente a este avance del culto, la Iglesia Católica local y el municipio han destinado numerosos esfuerzos por centralizar y disciplinar una práctica que dista de los rituales más canónicos y se acerca a las características de los carnavales bajtinianos. Dentro de estas acciones, se podría mencionar cómo se ha destinado un espacio en la periferia de la ciudad para la construcción de un santuario y evitar así que las procesiones interrumpan el tránsito en los centros visibles de la ciudad. Por otra parte, el municipio ha prohibido la utilización de fuegos de artificios, elemento fundamental en la realización de las procesiones y fiestas a la Virgen.

\section{Puntos de partidas teóricos-metodológicos}

El trabajo intenta pensar la construcción de identidades y legitimidades a partir de la práctica de vestimenta del culto a la Virgen de Urkupiña en la ciudad de Salta. La indagación se inscribe en las discusiones sobre comunicación y cultura de América Latina (Martín Barbero, 2003; Ticio Escobar, 2014) y retoma los estudios culturales (Hall, 2010), semióticos (Barthes, 1986) y sobre religiosidad desde vertientes antropológicas, históricas y sociológicas (Fogelman, 2000, 2005; Semán, 2004, 2006; Algranti, 2013; Dri, 2012, 2007). El objetivo del artículo es mirar los gustos legítimos de las agencias en la práctica de vestir la imagen y comprender cómo determinadas formas estéticas hablan de algunos intersticios de lo que se considera arte popular el cual se teje en y desde disputas, contestaciones y consentimientos a las lógicas de dominación en estrecha relación a las formas en las que se expresan y re-afirman las identidades sociales y religiosas.

El artículo entiende, desde los estudios culturales, que el proceso constitutivo de las identidades es un trabajo de la diferencia desde lo discursivo y desde los sistemas representacionales en lucha y/o conflicto, legibles según los regímenes de visibilidad imperantes en un estado de sociedad (Hall, 2003). 
La legitimidad, como categoría, pasa necesariamente por una cuestión de poder. Para Max Weber (2002) está más allá de un pacto racional realizado en función de conveniencias recíprocas, por tanto, no constituye un mero acuerdo utilitario entre ciertas partes interesadas. Un orden legítimo, en estricto rigor, es aquel que es tenido por verdadero, en cuanto se cree plenamente en él. A lo largo del trabajo se va explorando esta noción en relación a las percepciones de los promesantes construyen ciertas legitimidades en relación a determinados campos representacionales, es decir, imágenes de mundo que poseen ciertas cargas ideológicas (Cebrelli y Arancibia, 2005). En el caso de la práctica de vestir a la Virgen, se debe pensar en los gustos legítimos de las agencias para crear, comprar, realizar los vestidos de la imagen lo que constituye una representación (y una práctica) específica del culto en la ciudad de Salta (Nava Le Favi, 2019).

En relación al concepto de gusto, Pierre Bourdieu (1999) propone la existencia de un gusto de necesidad y un gusto de libertad en un claro intento de establecer cómo se vinculan las condiciones materiales con las culturales. El gusto de necesidad estaría relacionado con una estética pragmática y funcional a las condiciones de vida mientras que el gusto de libertad sólo podría ser comprendido por las facilidades que implica la posesión de un capital, como el económico (Bourdieu, 1999). De esta manera, habría una distribución desigual de lo legítimo -en este caso del gusto legítimo-, donde ciertos sectores aceptarían las imposiciones de la dominación.

Sin embargo, Grignon y Passeron (1989) critican la radicalización de la idea de legitimidad que plantea Pierre Bourdieu (1999) porque piensan que también se presentan legitimidades dentro de las culturas populares. Los autores proponen la idea de ambivalencia (Grignon y Passeron, 1989), es decir, cómo funciona la dominación y los espacios de autonomía que, en relación al gusto, permitirían pensar las elecciones de los actores en determinados contextos.

La noción de ambivalencia resulta fundamental para pensar la hegemonía en el lugar del arte popular. En este sentido, Ticio Escobar (2014) sostiene que se debe romper con el mito que toda dominación es una fuerza todopoderosa. En esa misma línea de sentido, García Canclini (1980) discute la noción teórica que considera al capitalismo como omnipotente y reflexiona que en sociedades tan complejas como el capitalismo periférico, ciertas formas pre-capitalistas les resultan necesarias al sistema para permitirle su reproducción equilibrada. Dentro de esas modalidades -y en el caso particular a estudiar-, debe pensarse en diversas cuestiones ancladas en la cultura andina que pervive en el culto, lo cual puede leerse desde la denominación de "Mamita" a la advocación, la cual responde a usos que se efectúan en cultos marianos de la región andina. Casos similares a este se presenta en la Virgen Nuestra Señora de la Candelaria que se festeja en Puno -Perú y en Humahuaca-, Argentina (Podjajcer y Mennelli, 2009). En ambos lugares, se presenta un proceso donde resulta intercambiable el término de Pachamama madre con virgencita-mamita, dando cuenta de un "complejo mapa de creencias católico populares vinculadas estrechamente a rituales y performances representados e identificados por sus actores como acciones sociales de su vida cotidiana" (ibídem, 2009, p. 90). Esa cartografía de creencias se presenta en Urkupiña también, a través de una continuidad de elementos rituales que se utilizan tanto en la Pachamama como en la devoción, entre los cuales se puede mencionar: las hojas de coca, la cerveza para la challa, los sahumerios e inciensos propios de la cultura andina. 
En el caso particular del ropaje a la Virgen, se puede hablar de ciertas expresiones pertenecientes al arte popular, es decir, el conjunto de formas estéticas producidas por sectores subalternos para apuntalar diversas formas sociales, vivificar procesos históricos y afirmar y expresas identidades sociales (Escobar, 2014). La precisión de la conceptualización de arte popular sólo es posible considerando la ambigüedad del término, es decir, es una categoría que implica una tensión constante: por un lado, son expresiones que muestran resquicios donde se abren posibilidades de nuevas representaciones a contramano, desviadas del sistema hegemónico o, paralelamente, se observan ciertos consentimientos que ceden a formas pertenecientes a las lógicas dominantes.

Antes de pensar cómo se configura el arte popular en el culto, es necesario situar la mirada en cómo se configura la devoción en Salta. Uno de los aspectos más importantes es la diversidad de espacios que ocupa Urkupiña, lo que permite pensar en una de las características del rizoma como es el principio de la conexión y heterogeneidad, es decir, en un rizoma, cada rasgo no remite únicamente a un rasgo lingüístico sino a eslabones semióticos con formas de codificación muy diversas poniendo en juego regímenes de sentidos distintos (Deleuze y Guattari, 1976).

En la ciudad, el principio de heterogeneidad se lee en términos espaciales porque la procesión se multiplica en barriadas y calles diversas, variables que dependen del lugar donde vive el promesante. También, se hace evidente en términos temporales porque no coinciden las fechas de todos los festejos en honor al culto pues se realizan de forma discontinua y esporádica desde fines del mes de julio y principios de agosto hasta diciembre. De esta manera, hay una multiplicidad de lugares -y tiempos-, donde realiza la devoción, la cual incluye tanto espacios públicos como privados.

Para mirar el proceso de vestimenta de la "Mamita", este trabajo retoma información obtenida de observaciones participantes, las cuales permitieron la presencia del investigador con el fenómeno observado para obtener datos sobre la realidad de los actores en sus propios contextos (Restrepo, 2016). Esta técnica se realizó en algunos de los espacios donde se emplaza la devoción en la ciudad y teniendo como eje los rituales que comprende el culto: las novenas en los hogares de los devotos, las procesiones en barrios y calles del microcentro salteño y las fiestas realizadas en las casas, salones alquilados para el evento entre otros durante el periodo 2009-2017.

Por otra parte, se retoma información obtenida de las entrevistas en profundidad a los devotos, dado que este tipo de técnica permite el acceso a las percepciones y valoraciones que los entrevistados poseen sobre situaciones, hechos y personajes (Restrepo, 2016). Esta técnica se puso en funcionamiento mientras se realizaban los rituales de la novena, las fiestas y las procesiones durante el periodo anteriormente mencionado. Las técnicas de recolección de información permiten mirar la manera en la que se configura el culto en general, y la práctica de la vestimenta del bulto, en particular.

El trabajo se estructura en una primera parte que intenta dar cuenta de una devoción rizomática, prestando principal atención, a la localización territorial del culto donde los devotos compran, realizan, venden las vestimentas, las cuales se constituyen en prácticas que atraviesan tanto el espacio público como privado. En un segundo momento, se intenta mirar la forma en la que las vestimentas a la Virgen se leen marcas de lo andino, lo popular y también lo hegemónico y masivo legible en los productos que conforman las industrias 
del creer. Por último, se entiende que ese proceso de vestimenta está enmarcado en diversas formas de humanizar el bulto y que responde, en algún punto, al gusto legítimo de las agencias.

\section{Vestir a la "Mamita": entre el espacio público y privado}

Victoria nació en Bolivia pero vive en Cerrillos - un municipio de la provincia de Salta-, hace más de 20 años. Ella y sus hijas son devotas del culto a la Virgen de Urkupiña y poseen un puesto de venta ambulante en la esquina de la Iglesia del Pilar, ubicada en el macro-centro de la ciudad salteña. El pequeño negocio cuenta con innumerables cantidad de alasitas ${ }^{4}$ propias de la devoción. Algunas son traídas de Cochabamba-Bolivia-ciudad de origen del culto-, y otras son fabricadas por la familia. Entre los árboles que rodean el puesto se coloca un tendedero donde se cuelgan numerosos vestidos para la Virgen los cuales tienen diferentes tamaños, colores y modelos.

José nació en Bolivia, Sucre. Su esposa e hijos nacieron en Salta. Ellos poseen un negocio familiar en la Galería Monalisa ubicada en el macro-centro de la ciudad, una feria que posee un altar a la devoción, el cual adornan entre todos los feriantes cada 15 de agosto. Para el día de la Virgen, cierran las puertas del local y le realizan grandes fiestas. Según José, la dueña del local donde se emplaza la feria es devota y por ello tiene afectividad a la "Mamita".

El negocio de José se dedica a la venta exclusiva de vestidos a la Virgen, los cuales confeccionan entre su esposa e hijas, un trabajo que implica un esfuerzo por ofrecer variedad a los dueños de los bultos: "tenemos vestidos de todos los tamaños, colores y modelos" (testimonio realizado en el mes de agosto del año 2016 en la Galería Monalisa de Salta). $\mathrm{Al}$ igual que Victoria, exhiben los vestidos para que el promesante elija, mida y finalmente compre "el que más le guste", dirá el comerciante.

Para Franco, un devoto de la zona más céntrica de la ciudad, la vestimenta constituye un aspecto primordial del culto. Así, él viaja hasta Bolivia porque las telas "son más brillantes y bordadas" (testimonio brindado en septiembre del año 2017), y encarga a una modista la realización del ropaje. Felicia, también compra telas de Bolivia, pero, además, ella confecciona el vestido y en ocasiones borda el manto de su Virgen.

También se ha mapeado experiencias de devotos que para poder afrontar los gastos que implica esta práctica reúnen dinero entre varios. Así, José -el comerciante-, considera que vestir a la imagen se relaciona con un factor de conexión con la divinidad, "va más allá del dinero, podes tener o no, ahorrar para comprarlo. Aquí viene gente de todas partes de la ciudad porque lo que importa no es cuanto sale, es cumplir con la Mamita" (testimonio realizado en el mes de agosto del año 2016 en la Galería Monalisa de Salta).

La vestimenta, entonces, funciona como un contra-don dentro del ritual y al mismo tiempo, como un lazo que permite tejer relaciones entre los promesantes y que no se configura por el capital económico de sus devotos, ya que éstos diseñan tácticas para invertir y/o conseguir la ropa en una clara demostración de agradecimiento. En otros casos relevados, las familias devotas suelen conversar y negociar hacia su interior sobre cuestiones referi- 
das al color y la forma que adquirirá para diferenciarse de años anteriores, una condición fundamental a la hora de la elección del ropaje.

De esta manera, el vestido de la Virgen se ubica entre el espacio público con negocios que se dedican a la venta exclusiva de este elemento ritual y, por otra parte, en el espacio privado, en los hogares de cada promesante, los cuales deciden confeccionar ellos mismos el ropaje. Aquí, resulta interesante retomar el concepto de industrias del creer paralelas, porque uno de los objetos más comercializados en la zona del macro y micro-centro salteño está anclado en el vestido como en los objetos que lleva la imagen: cetro, coronas, andas, entre otros, aspecto que no se presenta en devociones canónicas legítimas para la Iglesia salteña, como es el caso del culto del Milagro (Nava Le Favi, 2019).

\section{Entre aguayos y telas brillantes: lo popular, lo masivo y lo hegemónico}

Las telas de los vestidos son un índice de cómo se configura la práctica de la vestimenta al culto. En muchos casos, los vestidos se hacen con la tela de aguayo. Aquí se puede leer el espesor temporal de las representaciones, cual refiere a la forma en la que a una determinada representación se le van adosando modos de significar, de hacer, de percibir y de decir complejizando la estructuración de dichas representaciones. Este proceso es propio de las formaciones discursivas y de los modos de circulación que tienen (Cebrelli y Arancibia, 2005). El espesor temporal permite fechar de algún modo, otros tiempos de la historia y en este caso particular vinculado a lo andino. Si se indaga el origen de los aguayos, éstos sirven en la zona andina como abrigo, para cargar a los niños, llevar los alimentos y algunos objetos, el poncho y los costales. Más allá de los usos utilitarios, los textiles ayudan a establecer diferencias entre los grupos étnicos pertenecientes a los aymaras, urus o quechuas. Por otra parte, son una herramienta para construir una identidad pan-étnica frente a aquello que se identifica como no indígena (López García, 2009). En el caso de la Virgen de Urkupiña, se puede observar cómo diversos actores eligen vestir al bulto con aguayos, de algún modo, rememorando ese pasado andino en el culto y, por consiguiente, identificaciones que se asocian con lo indígena.

Por otra parte, hay vestidos que se realizan con telas brillosas, acampanadas. Los ropajes, aquí, están hipercodificadas (Eco, 2000) de acuerdo a los modelos capitalistas de vestimenta de las princesas más características del mercado global. En este sentido, se observa lo que Ticio Escobar (2014) relata en vinculación al arte popular: expresiones que manifiestan ciertas condiciones de la cultura popular pero que no por ello dejan de tener tensiones, consentimientos con lo hegemónico. Así, mientras algunos visten a la Virgen con aguayos otros, en cambio, ceden a la lógica dominante y visten sus bultos con vestidos brillosos y acampanados. En ambas situaciones, se presenta lo masivo porque los creyentes suelen recurrir a los negocios dedicados a la venta de estos elementos religiosos y, por otra parte, se observa una forma comunitaria de crear el ropaje que va más allá de la tela y el modelo elegido y que se observa en la manera de tejer redes para vestir el bulto. Allí, se puede observar cómo conviven múltiples maneras de pensar lo popular, lo masivo y lo hegemónico. 


\section{Entre el gusto y las formas de humanizar la Virgen}

La cercanía que establece el devoto con la divinidad a partir de la vestimenta es un índice de cómo se presentan contestaciones al sistema dominante religioso local, dado que uno de los pocos bultos que se viste por sus promesantes es el de Urkupiña mientras que los legitimados por el Arzobispado local -como el caso del Señor y la Virgen del Milagro en Salta- sólo pueden ser engalanados por actores autorizados por la Iglesia.

Este trabajo, entonces, entiende que el ropaje es un proceso que pasa -en parte-por el gusto legítimo de las agencias que visten de acuerdo a sus estilos, preferencias y trayectorias a la Virgen. Así, Franco, en el año 2017 vistió su imagen con aguayo: "porque la Virgen viene de Bolivia, entonces vestirla de aguayo es hacerle un homenaje a ella. Además, queda más colorida" (testimonio de Franco, 9 de agosto de 2017).

En un segundo sentido, también es una forma de humanizar el bulto, lo que expresa una forma de cercanía con la divinidad. En este punto, se hace necesario retomar la lógica barthesiana del signo, para comprender cómo se personifica una entidad divina: es necesario comprender cómo se produce la mitificación del culto, lo cual se vincula a la manera en la que la imagen -por efecto de la creencia- anula el significante y se vuelve significado, es decir, se obtura la imagen. Aquí, se conforma su sentido de divinidad, su carácter de imagen sagrada y, como tal, se vuelve símbolo (Dri, 2012, 2007). En ese aspecto, la imagen -también- es una sinécdoque porque el bulto representa una parte de todo un espectro de imágenes de mundo relacionadas a lo religioso.

Sin embargo, ese sentido de lo divino se vuelve a apropiar por los creyentes y se convierte en nuevo signo, "la Mamita", donde funcionan la personificación o prosopopeya, es decir, dotar y atribuir como realidad humana a algo no-humano: vestir, ofrecer comida, peinar, entran dentro de esta figura retórica como parte del eje sintagmático de contigüidad. La personificación de la imagen de Urkupiña suele estar acompañada de una fetichización del culto. Respecto a esta conceptualización, Rubén Dri (2012) explica que es un proceso que se presenta cuando el sujeto se desdobla en símbolo y pasa a verse a sí mismo en éste. Así, el sujeto le atribuye a la divinidad cualquier adquisición -material o espiritual-, e incluso llega a proyectarse en el símbolo y, por ello, algunos promesantes visten y adornan a la Virgen cómo ellos quisieran también ser vistos: “(...) yo le pongo pestañas a mi Virgen, ¿viste? Y usa colores fuertes. Es que a mí me gustan esos colores, yo los uso” (testimonio de María, 15 de agosto de 2016).

Este proceso de apropiación cultural de lo andino-boliviano o de los modelos capitalistas de princesas queda a elección de los promesantes y no constituye una práctica sectaria y jerarquizada, por el contrario, responde a un proceso rizomático que se entrama en lo popular legible en el espesor temporal de lo andino en la elección de los aguayos, por ejemplo. Paralelamente, se puede leer lo masivo en la enorme cantidad de negocios que ofrecen productos de esta industria del creer.

Frente a estos procesos complejos, la identidad se puede pensar en al menos dos sentidos: por un lado, en la identificación entre el creyente y la divinidad que proyecta sus gustos en el bulto y, por otro, de una identidad que atraviesa esos modelos de ropaje y que remiten a diversos espesores temporales como lo andino. Entonces, se puede hablar de formas legítimas de las agencias para vestir las imágenes otorgándole al culto una forma de construir 
identidad anclada en gustos, trayectorias que remiten a otros tiempos de la historia pero, principalmente, en la cercanía que puede establecer el devoto con la imagen divina a través de la práctica del ropaje, aspecto que no se presenta en otras devociones en Salta.

\section{Algunos cierres provisorios}

Este trabajo fue explorando brevemente el culto de Urkupiña como una forma de religiosidad rizomática en la ciudad de Salta. El análisis, se centra en cómo la práctica de vestimenta de la Virgen puede leerse en términos del "arte popular" el cual se teje en y desde disputas, contestaciones y consentimientos a las lógicas de dominación y, a la vez, en diálogo con lo masivo que en este artículo se abordó mediante el concepto de industrias del creer paralelas.

Así, se intenta atender a los intersticios en donde se teje las relaciones entre los promesantes con la divinidad pero, también, con el espacio que habitan y en vinculación con la manera en la que se piensa y vive la religiosidad en el territorio local.

El trabajo fue mirando cómo existen continuidades para habitar el espacio público y doméstico por parte del culto para luego pensar cómo la práctica del ropaje pone en relieve lo popular, lo masivo y lo hegemónico. De allí que se entiende que vestir a "la Mamita" es una forma de humanizar el bulto, volverlo cercano para las agencias, aunque esto implique a veces consentir a formas dominantes -vestirla como princesas-, o responder a lógicas andinas populares, que se vinculan más al mito de origen del bulto -al adornar las imágenes con aguayos-.

Paralelamente, se puede leer entre líneas cómo se articula allí lo identitario -tanto en forma individual como colectivamente-, y las legitimidades que se tejen desde la visión de los devotos lo que posibilita comprender la manera en la que una devoción migrante y asimilada por familias salteñas se configura en la ciudad.

\section{Notas}

1. Este proceso de territorialización (Deleuze y Guattari, 1997) en la ciudad de Salta, ya fue indagado en otros artículos (Nava Le Favi, 2018, 2019) donde se da cuenta de la forma en la que el culto se inscribe, por ejemplo, en palabras de agradecimiento de sus devotos que no dudan en colocar negocios con el nombre de la Mamita o inclusive realizar altares en sus comercios.

2. El término de lo popular es pensando en relación a la religiosidad: numerosos investigadores del culto como Barelli (2011) y Giorgis (2000) han caracterizado este tipo de devoción como parte de la religiosidad popular que se teje, principalmente, en lazos comunitarios.

3. La investigación de Joaquín Algranti (2013) se centra en objetos que son el resultado de procesos de industrialización de impronta netamente capitalista y los actores religiosos 
que poseen formas de organización y símbolos específicos. Su abordaje resulta novedoso porque tensiona la conceptualización de industria cultural asociada al ámbito religioso. En ese punto, este abordaje resulta trascendental pues propone dejar de separar dinero de religión, una división que obedece más a una teología católica o protestante que no puede ver las complejas relaciones entre la espiritualidad y la materialidad (Semán, 2013). Por otra parte, las industrias culturales paralelas es una conceptualización desarrollada por el teórico boliviano Marcelo Guardia Crespo (2003) a partir del análisis de los sistemas productivos que se realizan y que circulan en los mercados alternativos y populares de Bolivia. Para Víctor Arancibia (2015) la categoría de 'industrias culturales paralelas' permite analizar los consumos culturales de los mercados que en Argentina se denominan 'Truchos', 'Mercados de pulgas,' 'Mercados persas', entre otras nominaciones. En esos mercados paralelos, informales o alternativos se pueden adquirir flims, música, programas en copias de bajo costo (generalmente a un diez o cinco por ciento de su valor en los mercados formales). Aquí, se utiliza una combinación entre la propuesta de Crespo (2003) y Algranti (2013) para hablar de industrias del creer paralelas.

4. Las alasitas son elementos materiales que remiten a la reproducción en miniatura de bienes inmuebles: casas, autos y otros. En los festejos, las personas compran las alasitas como un acto simbólico de adquisición que le brindará la divinidad.

\section{Bibliografía citada}

Algranti, J. (2013). Las formas sociales de las mercancías religiosas. En J. Algranti (director), La industria del creer. Sociología de las mercanías religiosas. Buenos Aires: Editorial Biblos. pp. 13-34.

Arancibia, V. (2015). Nación y puja distributiva audiovisual. Identidades, memorias y representaciones sociales en la producción cinematográfica y televisiva del NOA (Tesis de doctorado) La Plata: Universidad Nacional de La Plata.

Barthes, R. (1986). Lo Obvio y lo obstuso. Imágenes, gestos y voces, Barcelona: Paidós.

Barelli, A. (2011). Religiosidad popular: el caso de la Virgen de Urkupiña en San Carlos de Bariloche. Revista Cultura y Religión, Santiago de Chile, v. 5, n. 1, p. 64-79

Bourdieu, P. (1999). La distinción. Criterios y bases sociales del gusto. Bs. As: Taurus.

Cebrelli, A. \& Arancibia, V. (2005). Representaciones sociales: modos de mirar y de hacer. 1. ed. Salta: CEPIHA-CIUNSa.

Deleuze, G. y Guattari, F. (1997). Mil Mesetas: capitalismo y esquizofrenia. Valencia: PreTextos.

Dri, R. (2012). “Símbolos religiosos en la construcción de la identidad popular”. En R. Dri (coord.) Símbolos y fetiches religiosos en la construcción de la identidad popular. Tomo 1. Buenos Aires: Editorial Biblios. pp 13-30.

. (2007). Símbolos religiosos populares. En R. Dri (coord.) Símbolos y fetiches religiosos en la construcción de la identidad popular. Tomo 2. Buenos Aires: Editorial Biblios. Eco, H. (2000). Tratado sobre semiótica general. 5º Edición. Ed. Lumen.

Escobar, T. (2013). El mito del arte y el mito del pueblo. Bs. As.: Editorial Ariel. 
Fogelman, P. (2000). Una cofradía mariana urbana y otra rural en Buenos Aires a fines del periodo colonial. Andes, núm. 11. pp. 3-34. (2005) Coordenadas marianas: tiempos y espacios de devoción a la virgen a través de las cofradías porteñas coloniales. Trabajos $y$ Comunicaciones, № 30 .

García Canclini, N. (1980). Culturas populares en el capitalismo, México: Ed. Nueva Imagen.

Giorgis, M. (2000). "Urkupiña, la virgen migrante fiesta, trabajo y reciprocidad en el boliviano gran Córdoba”. Revista Cuadernos Facultad de Humanidades y Ciencias Sociales, Universidad Nacional de Jujuy, No 13, pp. 233-250.

Guardia Crespo, M. (2003). Interacciones: la dimensión comunicacional de la cultura. Santa Cruz: UPSA.

Grignon, C. y Passeron, J. (1989). Lo culto y lo popular: miserabilismo y populismo en la sociología y en la literatura. Bs. As: Nueva Visión.

Hall, S. (2010). Sin Garantías, Colombia-Ecuador: Envión Editores. Instituto de estudios sociales y culturales Pensar. Universidad Javeriana Instituto de Estudios Peruanos Universidad Andina Simón Bolívar, sede Ecuador (2003). Introducción: ¿quién necesita identidad? En: S. Hall y P. Du Gay (comps.), Cuestiones de identidad cultural, Buenos Aires: Amorrortu, pp. 13-40.

López García, R (2009). El mundo animado de los textiles originarios de Carangas. Sección VI Cultura. Recuperado de: http://www.scielo.org.bo/pdf/rbcst/v12n27/v12n27a08.pdf Martín Barbero, J. (2003). De los medios a las mediaciones: comunicación, cultura y hegemonía. Bogotá: Convenio Andrés Bello.

Nava Le Favi, D. (2019). Ritualidades en disputa: Representaciones, identidades y territorios. (Urkupiña y El Milagro, periodo 2009-2017) (Tesis para optar el título de Doctor en Comunicación) Universidad Nacional de La Plata, La Plata. Recuperado de: http://sedici. unlp.edu.ar/handle/10915/73521. . (2018). "Bailar morenada en la ciudad. Espacio público, identidades y colonialidad en las experiencias de devotas a la Virgen de Urkupiña en Salta, Argentina”. Andamios, Revista de Investigación Social, $\mathrm{N}^{\circ} 15$, Vol 38.

Podjajcer, A. y Mennelli, Y. (2009). "La mamita y la pachamama: las performances del carnaval y la fiesta de nuestra señora de la Candelaria en Puno y en Humahuaca". Cuadernos de Facultad de Humanidades y Ciencias Sociales, Universidad Nacional de Jujuy, n 36, pp. 69-92.

Restrepo, E. (2016). Etnografías: alcances, técnicas y éticas. Bogotá: Envión Editores

Semán, P. (2013). "Las industrias culturales y la transformación del campo religioso: procesos y conceptos”. En J. Algranti, Joaquín y P. Semán (comp) La industria del creer: sociología de las mercanías religiosas. Buenos Aires: Biblos, 2013. p. 13-34.

. (2006). "El pentecostalismo y el rock chabón y la transformación de la cultura popular”, en D. Míguez y P. Semán (ed.), Entre Santos, cumbias y piquetes. Las culturas populares de la Argentina reciente. Buenos Aires: Biblos. pp. 197-218.

Intelectual

. (2004). Religiosidad popular: creencias y vida cotidiana, Buenos Aires: Capital

Turner, V. (1969). El proceso ritual. Taurus: Madrid.

Weber, M. (2006). Conceptos sociológicos Fundamentales. Alianza Editorial, Madrid, 2006 


\begin{abstract}
The work tries to think about the construction of identities and legitimacies from the practice of dress of the cult of the Virgin of Urkupiña in the city of Salta-Argentina. The inquiry returns to the approaches in communication and culture of Latin America, cultural studies, semiotics and on religiosity from anthropological, historical and sociological aspects. The objective of the article is to look at the way in which the legitimate tastes of the agencies are configured in the practice of dressing the image: in the case of Urkupiña it has a rhizomatic and community configuration that is also registered in an industry of belief of the devotion. This process enables us to understand how certain aesthetic forms speak of some interstices of what is considered "popular art" which is woven in and from disputes, answers and consents to the logics of domination in close relation to the forms in which they are expressed and re-affirm social and religious identities.
\end{abstract}

Keywords: Identities - Legitimations - Popular art - Industries of the belief - Marian cults.

Resumo: O trabalho tenta pensar sobre a construção de identidades e legitimidades a partir da prática de vestimenta do culto da Virgem de Urkupiña na cidade de Salta. A investigação retorna às abordagens em comunicação e cultura da América Latina, estudos culturais, semiótica e religiosidade a partir de aspectos antropológicos, históricos e sociológicos. O objetivo do artigo é olhar os gostos legítimos das agências se configuram na prática de vestir a imagem: no caso de Urkupiña, tem uma configuração rizomática e comunitária que também é registrada em uma indústria da crença específica do devoção. Esse processo nos permite compreender como certas formas estéticas falam de alguns interstícios do que é considerado "arte popular", que é entrelaçado em e a partir de disputas, respostas e consentimentos às lógicas de dominação em estreita relação com as formas em que se expressam. e reafirma as identidades sociais e religiosas .

Palavras chave: Identidades - Legitimações - Arte popular - Indústrias da crença - Cultos marianos.

[Las traducciones de los abstracts fueron supervisadas por el autor de cada artículo] 